\title{
Prediction of grip and key pinch strength in 978 healthy subjects
}

\author{
Felix Angst*1,2, Susann Drerup', Stephan Werle1, Daniel B Herren¹, Beat R Simmen and Jörg Goldhahn1,3
}

\begin{abstract}
Background: Hand strength is an important independent surrogate parameter to assess outcome and risk of morbidity and mortality. This study aimed to determine the predictive power of cofactors and to predict populationbased normative grip and pinch strength.

Methods: A representative population survey was used as the basis for prediction analyses $(n=978)$. Bivariate relationships between grip/pinch strengths of the dominate hand were explored by means of all relevant mathematical functions to maximize prediction. The resulting best functions were combined into a multivariate regression.
\end{abstract}

Results: Polynoms (up to the third degree) were the best predictive functions. On the bivariate level, height was best correlated to grip (46.2\% explained variance) and pinch strength (37.7\% explained variance) in a linear relationship, followed by sex, age, weight, and occupational demand on the hand. Multivariate regression provided predicted values close to the empirical ones explaining $76.6 \%$ of the variance for grip strength and $67.7 \%$ for pinch strength.

Conclusion: The five easy-to-measure cofactors sex, age, body height, categorized occupational demand on the hand, and body weight provide a highly accurate prediction of normative grip and pinch strength.

\section{Background}

The hand represents the most sophisticated and differentiated musculoskeletal tool in the human being, demanding the largest capacity of the nervous system in relation to its size. Full function and adequate strength of the hand are preconditions for dealing with the demands of daily life. Hand strength has been identified as an important factor predicting not only disability in musculoskeletal diseases such as rheumatoid arthritis [1], but also bone mineral density [2,3], and the likelihood of falls and fractures in osteoporosis [4,5]. It even predicts complications and general morbidity after surgical interventions [6], general disability and future outcome in older age [7-9], economic consequences of diseases [10] as well as causespecific and overall mortality in elderly people [5,11-13]. Arteriosclerosis is the most frequent cause of morbidity and mortality and grip strength is one of the strongest predictors of its consequences, e.g. myocardial infarction or stroke and post-event recovery $[12,14,15]$. In contrast,

\footnotetext{
* Correspondence: fangst@vtxmail.ch

1 Department of Upper Extremity and Hand Surgery, Schulthess Klinik, Lengghalde 2,8008 Zurich, Switzerland

Full list of author information is available at the end of the article
}

grip strength is almost completely independent from depression and return to work $[16,17]$.

In addition to its predictive value grip strength and key pinch strength are considered to be "objective" outcome parameters and are used to quantify outcome after orthopaedic interventions [18]. Many investigators normalize measured values such as percentage of the contralateral, non-affected side. However, when the contralateral side is also compromised by the underlying disease or its treatment, other benchmarks are required. Although numerous publications provide normative data for grip strength and key pinch strength, it would be helpful to predict the expected hand strength values for an individual based on easily measured factors [19].

Few studies examined predictors of hand strength itself. Strong predictors are sex, age, body height and mid-forearm circumference [20,21]. Weaker predictors are body weight and hand size measures [21]. Grip strength has often been taken as surrogate for overall strength but this should be done with caution since correlation of the two strength measures is high in many but also low in few settings [22]. Grip strength has a substantial north-south gradient from $24.2 \mathrm{~kg}$ in Denmark to $14.2 \mathrm{~kg}$ in Calabria 
in men [23,24]. Age-and gender-specific grip and key pinch strengths have recently been evaluated in a large population-based field study in Switzerland [25]. We used the data from that study to determine the predictive impact of various cofactors.

This study aimed to quantify the predictive power of easily assessable demographic and/or anatomical factors such as sex, age, occupational demands on the hand, body height, and body weight on grip and pinch strength. The second aim was to predict grip and pinch strength by a regression model of these factors.

\section{Methods}

\section{Data collection}

Subjects were selected at convenience at shopping centres, malls, secondary schools, senior sports groups, and senior residences (to find also immobile persons) in the German speaking part of Switzerland "to realize a random approach" [25]. Approval for the data collection of that study was obtained from the local ethics committee [25]. Each person had to undergo grip strength testing using a Jamar dynamometer and key pinch testing using a pinch gauge. Grip and pinch testing was performed in a standardized way according to the recommendations of the American Society of Hand Therapists as described in detail in [25]. Especially, the Jamar dynamometer was calibrated before the first measurement and was applied in the second handle position.

The average of three measurements per person was recorded and entered into a database together with the assessment of cofactors that had been identified as confounders in the clinical literature. They were: sex, age, body height, body weight, and demands on the hand due to occupational activity (classified into six categories: beyond sedentary, sedentary, light, medium, heavy, very heavy) as set out in the directory of occupational titles [26]. Dominant handedness was also determined by a standardized questionnaire [25].

All to the present analysis underlying data are described in detail in the descriptive original report [25]. In 2006 and 2007, data were obtained for 1023 persons. $4.4 \%$ were classified as ambidextrous and excluded from the analysis. The remaining 978 persons provided the data for the grip and pinch strength tables of the population survey and for the present study. There were 496 men and 482 women, of whom $88.3 \%$ were right-handed. The dominant hand was the right hand for $87.8 \%$ of the men and $88.8 \%$ of the women. Age ranged between 18 and 96 years and was classified into 5 -year groups. Strength data were determined by $\mathrm{n}=28$ to 46 male subjects and $n=26$ to 42 female subjects within the sex and age-group strata. Body height was on average $175.1 \mathrm{~cm}$ (standard deviation $7.1 \mathrm{~cm})$ for men and $163.7 \mathrm{~cm}(6.7$ $\mathrm{cm})$ for women. The corresponding values for body weight were $78.0 \mathrm{~kg}(11.8 \mathrm{~kg})$ for men and $64.1 \mathrm{~kg}(12.3$ $\mathrm{kg}$ ) for women. Frequency data within the occupational levels were as follows: beyond sedentary work: men $10.9 \%$ / women $10.1 \%$, sedentary work: $48.1 \%$ / $41.4 \%$, light work: $15.7 \%$ / $21.7 \%$, medium work: $20.3 \%$ / $26.2 \%$, heavy work: $5.0 \%$ / $0.6 \%$, very heavy work: $0.0 \%$ / $0.0 \%$. Detailed means and standard deviations of grip and pinch strength stratified by sex and 5 -year age groups are shown in table 1 , an extract of the tables of the original report.

\section{Analysis}

Grip and pinch strength in kg were predicted as independent variables for the dominant hand. First, bivariate curve adaptations were calculated using linear, quadratic, cubic, inverse, composite (inverse and polynom together), exponential, logarithmic, logistic, and s-shaped function characteristics of the dependent variable to find the optimal curve adaptation for each single cofactor explaining maximal variance of the dependent strength variable. The body mass index, $\mathrm{BMI}=$ weight $/$ height $^{2}$ was also taken into account by height and weight and by modeling all possibilities of linear, quadratic and inverse terms. In principle, every bivariate characteristic can be approximated by a polynom, $y=a_{0}+a_{1} x+a_{2} x^{2}+\ldots+a_{n} x^{n}$, the higher the degree $\mathrm{n}$ the more precise the approximation [27].

In a second step, all single optimal functions were combined together into a stepwise multivariate multifunctional regression to maximize explained variance. Regression coefficients, level of significance for predictive power, bivariate and partial correlations were determined. Addition and omission of one regression term had to significantly change the $r$ square (=explained variance) of the regression model for stepwise inclusion as being tested by the F-test $[28,29]$. All possible order of the variables were tested in adding / omitting to find the optimal model.

The coding was $0=\mathrm{f}, 1=\mathrm{m}$ for sex, age in years, height in $\mathrm{cm}$, weight in $\mathrm{kg}, 0=$ beyond sedentary, $1=$ sedentary, 2 = light, $3=$ medium, $4=$ heavy, $5=$ very heavy for the variable of occupational demands. All analyses were performed using the statistical software package SPSS 17.0 for Windows' (SPSS Inc., Chicago, IL, USA).

\section{Results}

\section{Grip strength}

The results of the bivariate and the mulivariate regressions of the cofactors with grip strength are shown in Table 2. All optimal models were polynoms, i.e. other functions like inverse or logarithmic did not explain more variance and did not predict grip strength better than a polynom. The optimal polynom was linear (i.e. grip strength $=a_{0}+a_{1}$ covariate) for sex, age, and height, qua- 
Table 1: Descriptive data of normal grip and pinch strength $(\mathbf{k g})$, dominant hand $(\mathbf{n}=\mathbf{9 7 8})$

\begin{tabular}{|c|c|c|c|c|c|c|c|c|}
\hline \multirow[t]{3}{*}{ Age } & \multirow{2}{*}{$\begin{array}{c}\text { Grip } \\
\text { M }\end{array}$} & \multicolumn{7}{|c|}{ Pinch } \\
\hline & & \multicolumn{3}{|c|}{$\mathbf{F}$} & \multicolumn{2}{|l|}{$M$} & \multicolumn{2}{|l|}{$\mathbf{F}$} \\
\hline & $\mathbf{m}$ & $s$ & m & $s$ & $\mathbf{m}$ & $s$ & $\mathbf{m}$ & $s$ \\
\hline $18-19$ & 51.2 & 6.6 & 32.0 & 4.8 & 9.5 & 1.8 & 6.9 & 1.2 \\
\hline $20-24$ & 53.9 & 8.7 & 33.4 & 5.4 & 9.8 & 1.4 & 6.5 & 1.3 \\
\hline $25-29$ & 53.0 & 7.5 & 34.3 & 5.7 & 10.1 & 1.4 & 6.8 & 0.9 \\
\hline $30-34$ & 55.0 & 7.1 & 33.8 & 5.9 & 9.9 & 1.5 & 6.9 & 1.2 \\
\hline $35-39$ & 55.9 & 7.9 & 35.8 & 6.7 & 10.4 & 1.5 & 7.1 & 1.4 \\
\hline $40-44$ & 54.2 & 8.1 & 36.0 & 6.0 & 10.3 & 1.5 & 7.2 & 1.0 \\
\hline 45-49 & 51.8 & 8.3 & 34.1 & 5.3 & 9.8 & 1.7 & 7.1 & 1.3 \\
\hline $50-54$ & 50.8 & 9.1 & 33.7 & 4.5 & 9.7 & 1.5 & 6.9 & 10 \\
\hline $55-59$ & 53.6 & 8.6 & 31.9 & 4.9 & 10.3 & 1.5 & 6.8 & 1.4 \\
\hline $60-64$ & 47.9 & 6.4 & 28.7 & 5.5 & 9.8 & 1.5 & 6.7 & 1.4 \\
\hline $65-69$ & 43.0 & 6.8 & 29.5 & 3.6 & 8.7 & 1.5 & 6.3 & 1.1 \\
\hline $70-74$ & 41.7 & 8.9 & 26.4 & 6.8 & 8.3 & 1.9 & 5.7 & 1.6 \\
\hline $75-79$ & 36.8 & 9.7 & 25.0 & 4.5 & 8.2 & 2.4 & 5.1 & 1.2 \\
\hline $80-84$ & 30.7 & 9.1 & 19.2 & 5.2 & 6.4 & 2.1 & 4.3 & 1.3 \\
\hline$\geq 85$ & 22.4 & 6.2 & 16.9 & 4.8 & 5.4 & 1.8 & 3.1 & 1.3 \\
\hline
\end{tabular}

Age in years. $\mathrm{n}=$ number of subjects. $\mathrm{M}=$ male, $\mathrm{F}=$ female. $\mathrm{m}=$ arithmetic mean, $\mathrm{s}=$ standard deviation.

dratic $\left(a_{0}+a_{1}\right.$ covariate $+a_{2}$ covariate $\left.^{2}\right)$ for age and weight, and cubic for occupational demand $\left(\mathrm{a}_{0}+\mathrm{a}_{1}\right.$ covariate + $\mathrm{a}_{2}$ covariate $^{2}+\mathrm{a}_{3}$ covariate $^{3}$ ). Height (46.2\% explained variance) had the highest bivariate predictive power, followed by sex, age, occupation and weight (see bivariate explained variance in Table 2).

All optimal bivariate model terms were combined to multivariate regression (Table 2). The multivariate partial correlation reflects the power of each covariate's term to

Table 2: Bivariate relationship and multivariate regression data of normal grip strength dominant (multivariate explained variance: $76.6 \%)(n=978)$

\begin{tabular}{|c|c|c|c|c|c|c|}
\hline \multirow[t]{2}{*}{ Covariates } & \multirow{2}{*}{$\begin{array}{c}\text { Bivariate } \\
\text { Correlation4 }\end{array}$} & \multicolumn{3}{|c|}{ Multivariate } & \multirow[b]{2}{*}{$\begin{array}{c}\text { Regression } \\
\text { coefficient }\end{array}$} & \multirow[b]{2}{*}{$\begin{array}{l}\text { Coefficient's } \\
\text { significance }\end{array}$} \\
\hline & & $\begin{array}{l}\text { Explained } \\
\text { variance5 }\end{array}$ & $\begin{array}{r}\text { Partial } \\
\text { correlation }\end{array}$ & $\begin{array}{l}\text { Explained } \\
\text { variance6 }\end{array}$ & & \\
\hline Constant & - & - & - & - & -28.148 & $<0.001$ \\
\hline Sex ${ }^{1}$ & 0.635 & $40.3 \%$ & 0.576 & $33.2 \%$ & 12.500 & $<0.001$ \\
\hline Age $^{1}$ & -0.460 & $29.6 \%$ & 0.187 & $3.5 \%$ & 0.372 & $<0.001$ \\
\hline $\mathrm{Age}^{2}$ & -0.506 & - & -0.263 & $6.9 \%$ & -0.005 & $<0.001$ \\
\hline Height $^{1}$ & 0.680 & $46.2 \%$ & 0.272 & $7.4 \%$ & 0.304 & $<0.001$ \\
\hline Weight ${ }^{1}$ & 0.460 & $21.7 \%$ & -0.022 & $<0.1 \%$ & -0.083 & 0.502 \\
\hline Weight ${ }^{2}$ & 0.446 & - & 0.041 & $0.2 \%$ & 0.001 & 0.198 \\
\hline Occupation ${ }^{1}$ & 0.377 & $24.4 \%$ & 0.254 & $6.5 \%$ & 12.293 & $<0.001$ \\
\hline Occupation ${ }^{2}$ & 0.307 & - & -0.225 & $5.1 \%$ & -5.865 & $<0.001$ \\
\hline Occupation ${ }^{3}$ & 0.284 & - & 0.200 & $4.0 \%$ & 0.897 & $<0.001$ \\
\hline
\end{tabular}

1 linear: coefficient times variable, ${ }^{2}$ quadratic: coefficient times variable ${ }^{2},{ }^{3}$ cubic: coefficient times variable ${ }^{3},{ }^{4}$ Correlation between grip strength and the covariates, e.g. grip strength with age (linear relationship), ${ }^{5}$ Explained variance of the optimal bivariate model (maximal explained variance) of grip strength with the covariates, e.g. grip strength $=a_{0}+a_{1}$ age $+a_{2} a g e^{2} .{ }^{6}$ Partial explained variance of the single regression terms within the optimal multivariate model (maximal explained variance). 
predict grip strength. Sex was the strongest multivariate term and explained $33.2 \%$ of the variance of grip strength. All other terms were similarly predictive and substantially weaker, i.e. height explained only $7.4 \%$ of the variance in the multivariate model. Weight played no predictive role. This means that all other covariates explained the variance of weight in the multivariate model. Leaving weight out of the regression reduces the explained variance from $76.6 \%$ to $76.1 \%$. Using the coefficients of the multivariate regression (second to last column of Table 2) now makes it possible to predict grip strength by using an equation:

Grip strength $(\mathrm{kg})=-28.148+12.500$ sex +0.372 age -0.005 age $^{2}+0.304$ height -0.083 weight +0.001 weigth $^{2}+12.293$ occupation -5.865 occupation $^{2}+0.897$ occupation $^{3}$.

For example, a 47-year old man $171 \mathrm{~cm}$ in height, weighing $72 \mathrm{~kg}$ and doing light work has an average grip strength of $50.3 \mathrm{~kg}$ in his dominant hand. The table of empirical values gives $51.8 \mathrm{~kg}$, resulting in an error of $2.9 \%$ [25]. If weight is excluded from the regression analysis, the result will be $51.1 \mathrm{~kg}$. The nondominant hand has an empirical value of $50.0 \mathrm{~kg}$ [25].

\section{Pinch strength}

The optimal bivariate models were the same as those for grip strength, i.e. they were all polynoms: linear for sex and height, quadratic for age and weight, and cubic for occupation. The results of the bivariate and the mulivariate regressions of the cofactors for pinch strength are shown in Table 3. The predictive power was highest for height (37.7\% explained variance), followed by sex, age, weight, and occupation for the bivariate models.

The multivariate regression revealed sex to be the most predictive variable (24.2\% explained variance) whereas all other covariates were of limited predictive power, especially weight. The regression equation is (Table 3 ):

Pinch strength $(\mathrm{kg})=-2.637+2.138 \mathrm{sex}+0.079$ age $-0.001 \mathrm{age}^{2}+0.034$ height +0.007 weight +0.001 weight $^{2}+2.641$ occupation -1.282 occupation $^{2}+0.195$ occupation $^{3}$

For the subject described above, this results in an expected dominant pinch strength of $11.1 \mathrm{~kg}$. The measured value of $9.8 \mathrm{~kg}$ corresponds to an error of $13.3 \%$ for the dominant hand. $9.2 \mathrm{~kg}$ are reported for the nondominant hand [25]. Leaving weight out of the analysis would result in $8.5 \mathrm{~kg}$.

\section{Discussion}

We quantified the predictive impact and predicted normative dominant grip and pinch strength by sex, age, body height and weight, and occupational demands on the hand based on a representative population survey [25]. The overall predictive power of these cofactors combined was very high - higher for grip than pinch strength
(76.6\% versus $67.7 \%$ multivariate explained variance). This was consistently true for the predictive power of the covariates in the bivariate and multivariate relationships.

The square roots of the explained variances mean that the data of the multivariate regression correlate to the empirically measured ones with values of 0.88 for grip strength and 0.82 for pinch strength [29]. For both strength parameters, polynominal equations were the best predictive functions with a maximal degree of 3 (for occupation). In the bivariate functions, height was the best and weight the worst predictor. In the multivariate approximation, sex was the most important predictor, and weight had virtually no predictive impact. The quadratic term of age approximated to the empiric curves much closer than the linear regression and reduced the high variance observed in older age, which was discussed as a possible weakness of the population survey [25].

The multivariate model provided a valid prediction of grip strength (error $2.9 \%$ ) but predicted pinch strength was less close to the measured one (error 13.3\%) as shown by the examples. However, the empirical data in the tables were only mean values stratified by sex and 5 -year age group and left out the cofactors body height, weight, and occupational demands on the hand [25]. Unequal distribution of important confounders such as occupational demands on the dominant hand may cause bias of the explicit data in the tables. For this reason and given the fact that predictive power of the multivariate models was high, it is possible that multivariate equations provide a better estimate of grip and pinch strength for a specific person than the empirically measured data. In addition, age taken as quasi-continuous variable into the regression will provide more precise normative data than obtained by means of strength out of age-grouped tables.

The difference in the grip and pinch strengths measured in a person suffering from a somatic (but not mental) disorder compared to the normative value may be used to predict various prognostic outcomes and risks as indicated in the wider literature. Examples are morbidity and mortality of rheumatological affections, vascular diseases, and general predictions as listed in the introduction [1-15]. Furthermore, hand/grip strength measurement is an easily performed "quick bedside test" [6]. Comparing clinical data to normative values allows the assessor to qualify (on average) whether the patient is at an elevated risk or not but few studies provided clinically feasible quantification of that risk. For example, the increment of $5 \mathrm{~kg}$ grip strength was associated with an average decrease of $10-15 \%$ in overall mortality after adjustment for confounders [11]. On the other hand, it is not possible to give a life expectancy in remaining years for a measured grip strength of $20 \mathrm{~kg}$ or $30 \mathrm{~kg}$ when $40 \mathrm{~kg}$ 
Table 3: Bivariate relationship and multivariate regression data of normal pinch strength dominant (multivariate explained variance: $67.7 \%)(n=978)$

\begin{tabular}{|c|c|c|c|c|c|c|}
\hline \multirow[t]{2}{*}{ Covariates } & \multirow{2}{*}{$\begin{array}{c}\text { Bivariate } \\
\text { Correlation4 }\end{array}$} & \multicolumn{3}{|c|}{ Multivariate } & \multirow[b]{2}{*}{$\begin{array}{c}\text { Regression } \\
\text { coefficient }\end{array}$} & \multirow[b]{2}{*}{$\begin{array}{l}\text { Coefficient's } \\
\text { significance }\end{array}$} \\
\hline & & $\begin{array}{l}\text { Explained } \\
\text { variance5 }\end{array}$ & $\begin{array}{r}\text { Partial } \\
\text { correlation }\end{array}$ & $\begin{array}{l}\text { Explained } \\
\text { variance6 }\end{array}$ & & \\
\hline Constant & - & - & - & - & -2.637 & 0.066 \\
\hline Sex $^{1}$ & 0.597 & $35.7 \%$ & 0.492 & $24.2 \%$ & 2.138 & $<0.001$ \\
\hline $\mathrm{Age}^{1}$ & -0.389 & $25.1 \%$ & 0.187 & $3.5 \%$ & 0.079 & $<0.001$ \\
\hline $\mathrm{Age}^{2}$ & -0.441 & - & -0.237 & $5.6 \%$ & -0.001 & $<0.001$ \\
\hline Height $^{1}$ & 0.614 & $37.7 \%$ & 0.146 & $2.1 \%$ & 0.034 & $<0.001$ \\
\hline Weight ${ }^{1}$ & 0.482 & $23.8 \%$ & 0.008 & $<0.1 \%$ & 0.007 & 0.796 \\
\hline Weight ${ }^{2}$ & 0.470 & - & 0.024 & $0.1 \%$ & 0.001 & 0.456 \\
\hline Occupation ${ }^{1}$ & 0.354 & $22.9 \%$ & 0.255 & $6.5 \%$ & 2.641 & $<0.001$ \\
\hline Occupation ${ }^{2}$ & 0.287 & - & -0.230 & $5.3 \%$ & -1.282 & $<0.001$ \\
\hline Occupation 3 & 0.265 & - & 0.203 & $4.1 \%$ & 0.195 & $<0.001$ \\
\hline
\end{tabular}

is expected by the norm. This raises important issues for future research.

One of the strengths of the study is the large representative sample providing valid normative data for the German speaking part of Switzerland and which can be expected to be valid for other European countries and the USA. Predictive power has been proven in various countries and cultures [1-15,20,21]. The regression formula can easily be programmed and allows quick determination of the norm for a specific person. For example, grip strength in Excel: fill in sex $(0=\mathrm{f}, 1=\mathrm{m})$ into field A1, age in years into $\mathrm{A} 2$, height in $\mathrm{cm}$ into $\mathrm{A} 3$, weigth in $\mathrm{kg}$ into A4, occupation ( 0 = beyond sedentary, $1=$ sedentary, $2=$ light, 3 = medium, 4 = heavy, 5 = very heavy) into A5, and program the formula of grip strength into A6: $28.148+12.5 * \mathrm{~A} 1+0.372 * \mathrm{~A} 2-0.005 * \mathrm{~A} 2 * \mathrm{~A} 2+0.304 * \mathrm{~A} 3-$ $0.083^{*} \mathrm{~A} 4+0.001^{*} \mathrm{~A} 4 * \mathrm{~A} 4+12.293^{*} \mathrm{~A} 5-$

$5.865 * \mathrm{~A} 5 * \mathrm{~A} 5+0.897 * \mathrm{~A} 5 * \mathrm{~A} 5 * \mathrm{~A} 5$. Get the result of grip strength in $\mathrm{kg}$ by "enter".

The limitations of the study are that the data may not be transferable to countries or populations with different socioeconomic conditions, especially to populations with high proportions of craftsmen. However, our grip strength data (see table 1) were comparable to those pooled by a meta-analysis of 12 studies of which 8 were conducted in the USA [19]. The prevalence of high demands on the hand due to occupational activity was low in our study, especially, there were no subjects reporting very high demands. Realistically, the prediction and regression data are only representative and valid for population-based normative values and not for disabled patients. The selection procedure of the volunteers was not really random. Furthermore, it was not possible to quantify health risks on the basis of the present data as discussed above. Finally, we did not further examine potentially predictive cofactors such as sporting or leisure activity level or comorbidities, e.g. smoking. However, there remained little space to explain additional variance since the regression models provided a good fit.

\section{Conclusions}

The five easy-to-measure cofactors sex, age, body height, categorized occupational demand on the hand, and body weight provide a highly accurate prediction of normative grip and pinch strength.

\section{Competing interests}

The authors declare that they have no competing interests.

\section{Authors' contributions}

All authors commented on the draft and the interpretation of the findings, helped to write and approved the final manuscript. FA was responsible for all parts of the work of the study, especially for the design, the analysis and the interpretation of the data, and wrote the original manuscript. SD and SW were responsible for the data acquisition and helped in the analysis of the data. DH helped in the interpretation of the data. BS and JG were responsible for the conception and the resources for the study.

\section{Acknowledgements}

We gratefully thank all volunteers for their participation in the study and Joy Buchanan for her English editing. 


\section{Author Details}

'Department of Upper Extremity and Hand Surgery, Schulthess Klinik, Lengghalde 2, 8008 Zurich, Switzerland, ${ }^{2}$ Rehaclinic Zurzach, Quellenstrasse, 5330 Bad Zurzach, Switzerland and 3Institute for Biomechanics of Swiss Federal Institute of Technology (ETH), 8090 Zurich, Switzerland

Received: 12 October 2009 Accepted: 19 May 2010

Published: 19 May 2010

\section{References}

1. Oken O, Batur G, Gündüz R, Yorganciogly RZ: Factors associated with functional disability in patients with rheumatoid arthritis. Rheumatol Int 2008, 29(2):163-166.

2. Barnekow-Bergkvist M, Hedberg G, PettersSon U, Lorentzon R: Relationships between physical activity and physical capacity in adolescent females and bone mass in adulthood. Scand J Med Sci Sports 2006, 16(6):447-455

3. Di Monaco M, Di Monaco R, Manca M, Cavanna A: Handgrip strength is an independent predictor of distal radius bone mineral density in postmenopausal women. Clin Rheumato/ 2000, 19(6):473-476.

4. Sirola J, Rikkonen T, Tuppurainen M, Jurvelin JS, Alhava E, Kröger H: Grip strength may faciliate fracture prediction in perimenopausal women with normal BMD: a 15-year population-based study. Calcif Tissue Int 2008, 83(2):93-100.

5. Ensrud KE, Ewing SK, Taylor BC, Fink HA, Cawthon PM, Stone KL, Hillier TA Cauley JA, Hochberg MC, Rodondi N, Tracy JK, Cummings SR: Comparison of 2 frailty indexes for prediction of falls, disability, fractures, and death in older women. Arch Int Med 2008, 168(4):382-389.

6. Mahalakshmi VN, Ananthakrishnan N, Kate V, Sahai S, Trakroo M: Handgrip strength and endurance training as a predictor of postoperative morbidity in surgical patients: can it serve as a simple bedside test? Int Surg 2004, 98(2):115-121.

7. Al Snih S, Markides KS, Ottenbacher KJ, Raji MA: Hand grip strength and incident ADL disability in elderly Mexican Americans over a seven-year period. Aging Clin Exp Res 2004, 16(6):481-486.

8. Rantanen T, Guralnik JM, Foley D, Masaki K, Leveille S, Curb JD, White L: Midlife hand grip strength as a predictor of old age disability. JAMA 1999, 281(6):558-560.

9. Bohannon RW: Hand-grip dynamometry predicts future outcomes in aging adults. J Geriatr Phys Ther 2008, 31(1):3-10

10. Flipon E, Brazier M, Clavel G, Boumier R, Gayet A, Le Loét X, Fardellone P: Is it possible to identify early predictors of the future cost of chronic arthritis? The VerA project. Fundam Clin Pharmacol 2009, 23(1):105-113.

11. Sasaki H, Kasagi F, Yamada M, Fujita S: Grip strength predicts causespecific mortality in middle-aged and elderly persons. Am J Med 2007, 120(4):337-342

12. Rantanen $T$, Volpato $S$, Ferruci L, Heikkinen E, Fried LP, Guralnik JM: Handgrip strength and cause-specific and total mortality in older disabled women: exploring the mechanism. J Am Geriatr Soc 2003 51(5):636-641.

13. Purser JLK, Kuchibhatla MN, Fillenbaum GG, Haring T, Peterson ED, Alexander KP: Indentifying frailty in hospitalized older adults with significant coronary artery disease. J Am Geriatr Soc 2006 54(11):1674-1681

14. Silventoinen K, Magnusson PK, Tynelius P, Batty GD, Rasmussen F: Association of body size and muscle strength with incidence of coronary heart disease and cerebrocvascular diseases: a populationbased cohort study of one million Swedish men. Int J Epidemiol 2009, 38(1):110-118.

15. Au-Yeung SS, Hui-Chan CW: Predicting recovery of dextrous hand function in acute stroke. Disabil Rehabil 2009, 31(5):394-401.

16. Watson J, Ring D: Influence of psychological factors on grip strength. $J$ Hand Surg (Am) 2008, 33(10):1791-1795.

17. Matheson LN Matheson, Isernhagen SJ, Hart DL: Relationships among lifting disability, grip force, and return to work. Phys Ther 2002, 82(3):249-256

18. Goldhahn J, Angst F, Simmen BR: What counts: outcome after distal radius fractures in aged patients. J Orthop Trauma 2008, 22(8 Suppl):S126-S130.

19. Bohannon RW, Peolsson A, Massy-Westropp N, Desrosiers J, Bear-Lehman $\mathrm{J}$ : Reference values for adult grip strength measured with a Jamar dynamometer: a descriptive meta-analysis. Physiother 2006, 92:11-15.
20. Chong CK, Tseng CH, Wong MK, Tai TY: Grip and pinch strength in Chinese adults and their relationship with antropometric factors. J Formos Med Assoc 1994, 93(7):616-621.

21. MacDermid JC, Fehr LB, Geiger KC: The effect of physical factors on grip strength and dexterity. Br J Hand Ther 2002, 7(4):112-118.

22. Bohannon RW: Is it legitimate to characterize muscle strength using a limited number of measures? J Strength Cond Res 2008, 22:166-173.

23. Rantanen T, Era P, Heikkinen E: Maximal isometric strength and mobility among 75-year-old men and women. Age Aging 1994, 23(2):132-137.

24. Jeune B, Skytthe A, Cournil A, Greco V, Gampe J, Berardelli M, AndersenRanberg K, Passarino G, Debenedictis G, Robine JM: Handgrip strength among nonagenarians and centenarians in three European regions. J Gerontol A Biol Sci Med Sci 2006, 61(7):707-712.

25. Werle S, Goldhahn J, Drerup S, Simmen BR, Sprott H, Herren DB: Age-and gender-specific normative data of grip and pinch strength in a healthy adult Swiss population. J Hand Surg Eur Vol 2009, 34(1):76-84.

26. Dictionary of occupational titles. In US Department of Labor Employment and Training Administration. Online version for Windows 4th edition. Washington, DC, USA; 1991.

27. Sachs L: Nichtlineare Regression (Non-linear regression). In Angewandte Statistik (Applied statistic) 9th edition. Edited by: Sachs L. Berlin, Germany: Spinger; 1999:560-567.

28. Backhaus K, Erichson B, Plinke W, Weiber R: Schrittweise Regressionsanalyse (Stepwise regression analysis). In Multivariate Analysemethoden (Multivariate methods of analysis) 10th edition. Edited by: Backhaus K, Erichson B, Plinke W, Weiber R. Berlin, Germany: Spinger; 2003:104-111.

29. Abrahamson JH, Abrahamson ZH: Measures of strength. In Making sense of data. A self-instruction manual on the interpretation of epidemiologic data 3rd edition. Edited by: Abrahamson JH, Abrahamson ZH. Oxford, UK: Oxford University Press; 2001:200-201.

\section{Pre-publication history}

The pre-publication history for this paper can be accessed here: http://www.biomedcentral.com/1471-2474/11/94/prepub

doi: 10.1186/1471-2474-11-94

Cite this article as: Angst et al., Prediction of grip and key pinch strength in 978 healthy subjects BMC Musculoskeletal Disorders 2010, 11:94

\section{Submit your next manuscript to BioMed Central and take full advantage of:}

- Convenient online submission

- Thorough peer review

- No space constraints or color figure charges

- Immediate publication on acceptance

- Inclusion in PubMed, CAS, Scopus and Google Scholar

- Research which is freely available for redistribution
C) Biomed Central 